\title{
Art competition: Sleep and Breathing 2009
}

\author{
Nikolaus C. Netzer
}

Published online: 19 December 2007

(C) Springer-Verlag 2007

\section{To all artists in painting and photographic artists:}

Sleep and Breathing is holding again an art competition for four cover issues of the journal in 2009. The rules of participation are as follows:

Submissions for the competition must be original own art not photographs of art from other artists like sculptures or paintings.

Previously, several pictures were received that were taken of sculptures and paintings of famous artists in museums castles and churches. This is not the intention, and printing of these photographs would infringe copyright laws.

\section{The rules}

Participants may submit via email pictures in high-resolution (minimum of 4 Megapixels) formats of four paintings of their own artwork or four photographs of their own artwork with the topic of Sleep and Breathing (a sample of an own art work photography is given below). Submissions to be sent directly to Niki Netzer email: nikinetzer@yahoo.com

The pictures must be accompanied by an informal cover letter declaring that the artist gives the copyright to Springer Publishers for the print of the art on the four covers of Sleep and Breathing during the year 2009.

\footnotetext{
N. C. Netzer $(\square)$

Hermann Buhl Institute for Hypoxia and Sleep Medicine

Research, Paracelsus Medical University Salzburg,

Salzburgerstr. 7

83435 Bad Reichenhall, Germany

e-mail: Nikinetzer@yahoo.com
}

If a photo, please ensure that the model has agreed to have his/her photo submitted to the competition and in case of acceptance agrees to have his/her photo appear on the cover page of the journal.

The winner will be selected by a jury of art experts and the editorial board. Artists accept these rules of submission noting that the jury and editorials board final decision is final. No correspondence will be considered.

The winner will receive prize money of $€ 1,500$. The jury has the right to decide to give two or more participants first prizes. The prize money would then be divided between the number of participants/artwork.

Deadline for submissions is 30 June 2008.

Here is an example of an own art work photograph (Title: "Fake a dream," Venice, Centro Storico, Arsenal, Italy, Spring 2004, by Nikolaus Netzer).

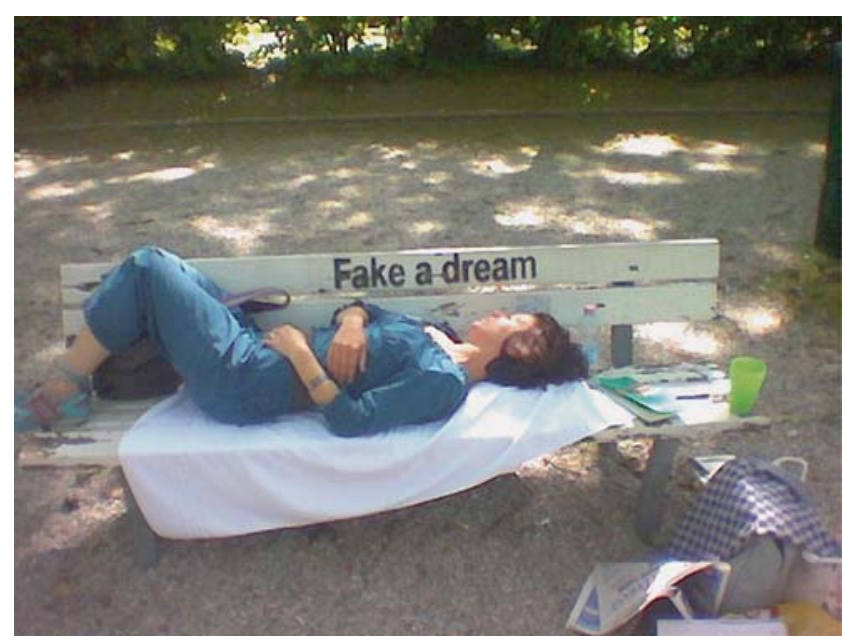

